\title{
DIFERENTES MÉTODOS DE ABATE DO PESCADO PRODUZIDO EM AQUICULTURA, QUALIDADE DA CARNE E BEM ESTAR DO ANIMAL
}

\author{
Carlos Eduardo Campos Freire' e Alex Augusto Gonçalves ${ }^{2}$ \\ 'Professo do Instituto Federal de Educação, Ciência e Tecnologia (IFRN), Câmpus Cidade Alta \\ ${ }^{2}$ Professor Adjunto do PPCA da Disciplina de Tecnologia, Inspeção e Controle de Qualidade do Pescado \\ E-mail: eduardo.freire@ifrn.edu.br ${ }^{1}$-alaugo@gmail.com ${ }^{2}$
}

Artigo submetido em julho/2012 e aceito em dezembro/2013

\section{RESUMO}

O pescado constitui uma importante fonte de proteína animal para a população humana. Somada a essa importância, os alimentos oriundos do ambiente aquático, principalmente os peixes de origem marinha, apresentam propriedades e compostos que ajudam a prevenir determinados problemas de saúde. Além disso, a carne magra é recomendada para evitar problemas de saúde e aumentar a longevidade das pessoas. Um aspecto negativo do pescado consiste em sua elevada capacidade de deterioração por processos físicos, químicos e biológicos. Os métodos de abate, nesse sentido, tornam-se importantes fatores a serem considerados para uma melhor preservação das características do alimento, visto que, durante o processo de abate o animal pode se debater bastante fazendo com que as reservas de energia sejam reduzidas drasticamente promovendo o acúmulo de ácido lático, favorecendo a ação de enzimas proteolíticas e levando um sabor indesejado ao produto. Esta revisão descreve os principais mecanismos de abate, publicadas na literatura, nos diferentes tipos de pescado e sua influência na qualidade da carne. Outro aspecto importante, descrito e analisado, foi o bem-estar do animal durante o processo de abate.

PALAVRAS-CHAVE: Método de abate, qualidade do pescado, vida de prateleira.

\section{DIFFERENT METHODS OF SLAUGHTER OF SEAFOOD PRODUCED IN AQUACULTURE, MEAT QUALITY AND ANIMAL WELFARE}

\begin{abstract}
Sea food is an important source of animal protein for the human population. Added to this importance, the aquatic food, especially the marine fish, contain compounds and properties that could help top event certain health problems. Moreover, the lean meat is recommended to avoid health problems and increase the people longevity. A negative aspect of the seafood is the high capacity of deterioration by physical, chemical and biological processes. Accordingly, the slaughter's methods become important factors to be considered for a better preservation of food characteristics, since,
\end{abstract}

during the slaughter process, the animal can shake off fairly making the energy reserves reduced drastically promoting the accumulation lactic acid, favoring the action of proteolytic enzymes and causing un wanted taste to the product. This review describes the mechanisms of slaughter, published in the literature, in different sea food species and the influence on final meat quality. Another important aspect described and analyzed, it was the wellness of the animal during the slaughter process.

KEYWORDS: Method of slaughter, quality seafood, shelf life. 


\section{DIFERENTES MÉTODOS DE ABATE DO PESCADO PRODUZIDO EM AQUICULTURA, QUALIDADE DA CARNE E BEM ESTAR DO ANIMAL.}

\section{INTRODUÇÃO}

Diante da crescente crise ambiental que se instala nas nações onde cada vez mais as florestas sofrem pressão causada por culturas de bovinos, ovinos, suínos e ruminantes de uma maneira geral, o pescado torna-se uma fonte rica em proteína de origem animal e pouco impactante em relação a outras culturas. A produção de pescado no ano de 2011 foi de, aproximadamente, 154 milhões de toneladas fornecendo cerca de 18,6kg por pessoa ao ano. Isso representa aproximadamente $1 / 4$ da oferta mundial da proteína de origem animale há pelo menos uma década, as taxas de crescimento da aquicultura mantêm-se em patamares superiores a $10 \%$ ao ano (FAO, 2012).

Apesar de constituir essa importante fonte, ocorre significante perda de pescado durante o pós-captura, atingindo marcas de cerca de 10 a 12 milhões de toneladas/ano, e ainda aproximadamente mais 20 milhões de toneladas de peixes/ano são rejeitados no mar, prejudicando a segurança alimentar (FAO, 2012).

Para manter a qualidade do pescado, o abate é um importante gargalo (RIBAS et al., 2007). O estresse associado a este manejo, afeta diretamente na redução do tempo de rigor mortis, proporcionando principalmente diminuição da vida de prateleira (ROBB; KESTIN; LINES, 2000).

Muitos peixes apresentam hábitos ativos podendo debater-se bastante antes do abate, prejudicando a qualidade da carne (STANSBY, 1968). A diferença na qualidade dos produtos produzidos em cativeiro em relação aos que são capturados no ambiente natural consiste na garantia de que os produtos gerados serão entregues vivos aos beneficiadores, englobando o sistema de captura, que vai da despesca e transporte de peixes vivos até o abatedouro (SOUZA, 2001).

Outro fator que deve ser considerado é o método de abate humanitário, visto que o consumidor final preocupa-se cada vez mais com a forma de abate confrontando aos maus tratos sofridos pelos animais (PEDRAZZANI, 2007).

Este artigo visa reunir as informações relevantes existentes na literatura sobre os métodos de abate e a qualidade do pescado, bem como os impactos negativos causados ao produto e o bem-estar do animal durante o processo de abate.

\section{METOdOLOGIA}

O trabalho caracteriza-se como uma revisão bibliográfica com abordagem qualitativa. $\mathrm{Na}$ coleta de dados foram utilizadas análises bibliográficas que relacionaram os métodos de abate, bem-estar animal e qualidade do pescado. 


\subsection{A QUALIDADE DO PESCADO}

Para se obter excelência em qualidade no pescado é necessário considerar se os animais foram cultivados (por meio de técnicas de aquicultura) (CASTAGNOLLI, 1992) ou coletados em ambiente natural. Dentre as técnicas de aquicultura alguns cuidados devem ser observados. A operação de limpeza tem muitas vantagens: reduz o consumo de oxigênio, e o impacto das doenças bacterianas e parasitárias e, por último, mas não menos importante, garante maior higiene e boas características organolépticas ao peixe capturado, evitando-se indesejáveis materiais que entram nas brânquias e boca (RIBEIRO et al., 2005).

Em tanques de concreto a operação é mais fácil e possível em todas as condições meteorológicas (MARDINI \& MARDINI, 2000). Os tanques têm geralmente 1-2 metros de profundidade e, muitas vezes, é possível recolher os peixes sem entrar no tanque.

No cultivo de pescado em gaiolas de ambiente dulcícola, marinho ou em tanques escavados, é preciso cuidado ao tirar o peixe fora da água. Esta deve ser uma operação rápida para evitar que os peixes percam sua escala de cor e para preservar a aparência e o brilho da pele. Em casos extremos, dependendo da forma de manejo, pode ser causada hemorragia generalizada nos animais (URBINATI; CARNEIRO, 2004).

Visando utilizar processos que garantam a segurança alimentar, a indústria vem ampliando sua preocupação com a qualidade do alimento (HUSS, 2003). Dentre os atributos significativos de qualidade do pescado, o grau de frescor constitui atributo expressivo de qualidade do pescado, pois apresenta importante relevância determinando um dos principais critérios de aceitação do produto (NUNES et al., 2007).

\subsection{PRINCIPAIS MÉTODOS DE ABATE}

\subsubsection{Abate por choque térmico (termonarcose)}

Como destaca Caggiano (2002), o abate ideal deve ser fácil, rápido, higiênico, e deve causar o menor prejuízo possível à integridade da carne. Com este método, em poucos minutos, os peixes são refrigerados a partir da temperatura do mar $\left(12-28^{\circ} \mathrm{C}\right)$ a cerca de $2-3^{\circ} \mathrm{C}$.

Um dos métodos de abate mais usual é a imersão do peixe em água gelada (ASHLEY, 2007) que consiste em submergir os peixes em água gelada, a uma temperatura em torno de 1 o $C$, até a morte. A hipotermia causa insensibilização nos animais, sendo aplicado em trabalhos que avaliam tanto questões de bem-estar dos peixes, como sua relação com a qualidade do produto final (LAMBOOIJ et al., 2002).

$A$ água gelada deve ser saturada $\operatorname{com} \mathrm{CO}_{2}$, que tem um poder anestésico e, portanto, os peixes sofrem menos stress e tornam-se menos sensíveis à dor (ASHLEY, 2007).

Em trabalho realizado por Pedrazani et al. (2008), o índice de rigor-mortis (IRM) não apresentou diferenças significativas $(p>0,05)$ entre o seç̧ão de medula e o termonarcose pois a musculatura dos peixes apresentou rigor completo entre 8 e 11 horas, independentemente do tratamento. 


\subsubsection{Seç̧ão da medula}

Método utilizado, geralmente, com o auxílio de uma faca afiada, com lâmina unilateral ou bilateral, introduzida a partir de um dos opérculos até atingir a medula. Considera-se o método que deixa o peixe com maior insensibilidade a dor (PEDRAZZANI et al., 2007) muito embora, parte da população acredite na senciência dos animais durante o abate.

A qualidade da carne nesse tratamento apresentou rigor completo entre 8 e 11 horas, segundo Pedrazzani(2007) sem apresentar diferenças significativas de métodos mais tradicionais como a termonarcose, mantendo assim os padrões de qualidade das proteínas do pescado.

\subsubsection{Imobilização de crustáceos e peixes utilizando impulsos elétricos}

Os crustáceos podem ser abatidos pelo sistema Sistema de Imobilização e Abate de Crustáceos (SIAC) ( que trata-se de um equipamento confeccionado em fibra de vidro capaz de imobilizar ou abater crustáceos imersos em água doce ou salgada, à temperatura ambiente. A voltagem e o tempo de exposição e duração dos pulsos elétricos são regulados de acordo com a espécie de crustáceo. Observou-se nesse procedimento que, sensorialmente, após o cozimento, a carne dos caranguejos soltou-se mais facilmente da carapaça (OGAWA et al., 2008).

Em peixes, os atordoamentos elétricos são aplicados apenas na cabeça. Esse parece ser o método causador de menos perturbação ao animal ao se analisar dados comportamentais e de reflexos cerebrais(CONTE, 2004).

Em trabalho de Lines e Kestin (2005) compararam-se vários métodos de abate atordoamento por $\mathrm{CO}_{2}$, sangria das brânquias, choque térmico e atordoamento elétrico - para a truta, chegando-se a conclusão que o atordoamento elétrico de fase única por 60 segundos e corrente elétrica de $1000 \mathrm{~Hz}$, apesar de causar hemorragias no animal, é o que causa menos danos à carcaça.

\subsubsection{Abate por sangria das brânquias}

O método de abate por sangria é realizado por perfuração das brânquias, e posteriormente o peixe é submerso em água gelada, em temperatura de $1^{\circ} \mathrm{C}$ (OLSEN, 2006). Para a garantia do bem-estar animal, este método é realizado em conjunto com prévia insensibilização, com $\mathrm{CO}_{2}$ (ROTH et al., 2007), estimulação elétrica (LAMBOOIJ et al., 2002) e hipotermia (LAMBOOIJ et al., 2002). Entretanto, diversas indústrias utilizam a sangria sem nenhuma insensibilização, inclusive no Brasil.

Erikson et al (1999) realizando trabalhos com o salmão (Salmo salar) concluíram que o status de energia do músculo parecia aumentar com o resultado da hemorragia, não tendo o sangramento efeitos adversos sobre a frescura da carne.

\subsubsection{Abate por asfixia em $\mathrm{CO}_{2}$}

Nesse tipo de abate os peixes são acondicionados vivos em tanques, apresentando $1 / 4$ do volume de água onde é bombeado $\mathrm{CO}_{2}$ presente em cilindros fora do tanque através de 
mangueiras por cerca de 10 minutos. Esse método é utilizado com o intuito de insensibilizar o animal, mas apresenta grande nível de letalidade (ALBUQUERQUE et al. 2004).

Em trabalho realizado com truta, carpa e enguia Marx et al. (1997) concluíram que os resultados da asfixia por $\mathrm{CO}_{2}$, comparados à técnica manual (pancada na cabeça) e atordoamento utilizando eletricidade foram os que revelaram menores valores de $\mathrm{pH}$ e maior capacidade de retenção de água.

\subsection{METABOLISMO PÓS-ABATE}

Segundo Viegas (2004) a relativa escassez de informações sobre como melhor conservar os peixes após a despesca evidencia a necessidade da realização de estudos para se estabelecer os melhores métodos de abate, as condições de armazenamento após a morte e vários outros fatores que facilitam os processos e melhoram a qualidade geral dos peixes de água doce.

Modificações pós-morte são induzidas por dois fenômenos: a autólise celular e a atividade bacteriana. O primeiro começa logo em seguida ao óbito e,o segundo um pouco mais tarde. Após a morte, o oxigênio não chega as células, por isso elas tentam sobreviver à custa de energia imediatamente disponível (ATP) e da glicólise anaeróbia, que produz ácido lático (então diminui o valor do $\mathrm{pH}$ ), o que acontece no período pré rigor, quando os peixes tem os músculos relaxados (CAGGIANO, 2000).

\subsection{IMPACTOS NEGATIVOS NA QUALIDADE DO PRODUTO DEVIDO AO MÉTODO DE ABATE}

Por se tratar de questão importante no bem-estar dos peixes, o estresse na piscicultura tem se tornado uma preocupação considerável, segundo Ashley (2007). Os aspectos éticos também são considerados na cadeia produtiva (LAMBOOIJ et al., 2006). Os efeitos negativos na produção (URBINATI; CARNEIRO, 2004) e na alteração dos atributos de qualidade da carne são outros fatores levados em consideração na cadeia produtiva.

A definição de estresse é bastante ampla, mas de maneira geral, é um conjunto de respostas do organismo animal diante de estímulos desagradáveis, agressivos e ameaçadores (URBINATI; CARNEIRO, 2004). A severidade, duração e velocidade do estressor são fatores que influenciam na qualidade da carne. $O$ estresse pode ocorrer pelo manejo da produção, como pela densidade de estocagem, pelo transporte e pelo abate (LAMBOOIJ et al, 2002).

As respostas ao estresse funcionam como um mecanismo que permite aos peixes preservar a saúde frente às ameaças dos estressores (LIMA et al., 2006). A resposta com finalidade adaptativa apresenta como aspecto central a realocação da energia metabólica de atividades de investimento, como o crescimento e a reprodução, para atividades de restabelecimento da homeostase, como a respiração, locomoção, regulação osmótica e reparação tecidual (WEENDELAR BONGA, 1997)

A dor e o estresse no momento do abate fazem com que reações químicas aconteçam acelerando o processo de rigor-mortis. Segundo Poli et al. (2005), acontece também a redução das reservas de glicogênio e aumenta o nível de ácido lático da musculatura dos peixes. Isso faz 
com que o pH da carne fique baixo, acelerando a degradação do pescado pela liberação de enzimas proteolíticas, ou seja, o método de abate interfere na qualidade final do produto, pois o estresse causado antes e durante o abate é inversamente proporcional ao tempo de prateleira do pescado (LOWE et al., 1993; KUBITZA, 1999; POLI et al., 2005).

Diferentemente do exposto, a literatura cita métodos considerados inadequados do ponto de vista de bem-estar animal e que alteraram significativamente a qualidade da carne do pescado. Roth et al. (2002) encontraram diferenças no rigor mortis entre peixes insensibilizados por $\mathrm{CO}_{2}$, eletricidade e percussão. $\mathrm{O}$ estresse causado durante a insensibilização por $\mathrm{CO}_{2}$ antecipou o início e término da fase de rigor, acelerando o amaciamento do tecido muscular post mortem e, consequentemente, o processo de decomposição da carne, quando comparado com os outros tratamentos.

Em trabalho realizado por Albuquerque et. al (2004), os dados coletados através do Método do Índice da Qualidade (MIQ) indicaram que no início do armazenamento em gelo os peixes insensibilizados com $\mathrm{CO}_{2}$ apresentavam ótimo estado de frescor permanecendo estáveis nesta condição durante os 7 primeiros dias de armazenamento. Entre o 12 e o 17o dia de armazenamento, porém, foi observado o aparecimento de opacidade no cristalino do olho e descoloração das guelras. Mudanças similares foram observadas nos peixes insensibilizados com gelo a partir do 70 dia (opacidade do cristalino) e 5 dia (descoloração das guelras). Isto sugere que os peixes atordoados com $\mathrm{CO}_{2}$ podem manter uma condição melhor do cristalino do olho e das guelras do que os peixes atordoados com gelo. Estas características são importantes no peixe fresco podendo comprometer a apreciação de qualidade feita pelo consumidor (HUIDOBRO \& TEJADA, 2000).

\subsection{BEM-ESTAR ANIMAL DURANTE O ABATE}

Os estudos relacionados ao bem-estar animal apontam a densidade de lotação dos viveiros, o transporte e as técnicas de abate como os principais pontos críticos relativos a senciência do animal que consiste em ter consciência em sensações e sentimentos. (PEDRAZZANI, 2008)

Para avaliar se um método de insensibilização é satisfatório do ponto de vista de bemestar animal, é importante determinar a rapidez do processo. Kestin et al. (2002) elaboraram um protocolo para avaliar a efetividade dos métodos utilizados para insensibilização e abate através da função cerebral.

Para realizar a insensibilização do peixe 10 a 15 minutos antes do abate, a maioria dos frigoríficos procede sua imersão em gelo ou água gelada para realizar a termonarcose ou choque térmico como citado por Robb \& Kestin (2000). Para um abate ser considerado humanitário, a insensibilização deve ser imediata ou realizada de forma a evitar a dor e o sofrimento.

Em contrapartida, estudos realizados por Hastein et al. (2005), comprovam que a asfixia dos peixes em gelo anteriormente ao abate pode demorar mais de 15 minutos, podendo levá-lo a problemas osmorregulatórios e a exaustão. 
Portanto, a asfixia em gelo e o choque térmico são métodos fortemente questionáveis do ponto de vista do bem-estar animal (ROBB et al., 2000; CONTE, 2004). A seç̧ão de medula seguida da sangria das brânquias poderia ser considerada um método alternativo para a substituição da termonarcose, proporcionando perda de consciência mais imediata dos peixes (PEDRAZZANI et al., 2007)

\section{CONSIDERAÇÕES FINAIS}

Os métodos de abate constituem importante fator para a qualidade do pescado consumido no Brasil e no mundo. Esses métodos vêm tornando-se cada vez mais humanizados, passando por processos de sensibilização, devido às pressões da sociedade para que os animais não sofram estresse excessivo.

Além disso, o consumo de glicogênio pelo animal durante o estresse pré-abate pode comprometer a qualidade final do produto que vai ser levado ao consumidor.

Dentre os métodos analisados nesse trabalho, aquele que apresentou melhor desempenho em relação à qualidade do pescado foi a termonarcose. Para análise da senciência animal, a secção da medula e o corte das brânquias demonstraram menor tempo para abate, levando o animal a menor sofrimento.

\section{REFERÊNCIAS BIBLIOGRÁFICAS}

1. AlBuquerque, W. F. de; ZAPATA, J. F. F., ALMEIDA, R. S. Estado de frescor, textura e composição muscular da tilápia-do-Nilo (Oreochromis niloticus) abatida com dióxido de carbono e armazenada em gelo, Revista Ciência Agronômica, Vol. 35, Número Especial, out., 2004: $264-271$

2. ASHLEY, P. J. Fish welfare: current issues in aquaculture. Applied Animal Behaviour Science, Amsterdam, v. 104, p. 199-235, 2007.

3. CAGGIANO, M. Quality in harvesting and post-harvesting procedures -influence on quality. Fish freshness and quality assessment for sea bass and sea bream. FILE NAME MEGEFORMAT, 2002.

4. CASTAGNOLLI, N. Piscicultura de Água Doce. Ed. FUNEP, Jaboticabal, SP, 1992, 189p.

5. CONTE, F.S. Stress and the welfare of cultured fish. Applied Animal Behaviour Science, v. 86, p. 205-223, 2004.

6. ERIKSON. U.,SIGHOLT. T., RUSTAD. T., EINARSDOTTIR. I.E. and JØRGENSEN. L. Contribution of Bleeding to Total Handling Stress During Slaughter of Atlantic Salmon. Aquaculture International Volume 7, Number 2, 101-115, 1999.

7. FAO. 2012. World review of fisheries and aquaculture. Disponível em: <http://www.fao.org/docrep/016/i2727e/i2727e01.pdf >Acesso em: 17/07/2012>

8. HASTEIN, T.; SCARFE, A.D.; LUND, V.L. Science-base dassessment of welfare: aquatic animals. Revue Scientifique et Technique Office International des Epizooties, v.24, n.2, p.529-547, 2005. 
9. HUIDOBRO, A., PASTOR, A., \& TEJADA, M. (2000). Quality Index Method developed for Raw Gilthead Seabream (Sparus aurata). Journal of Food Science, 65(7), 1202-1205.

10. HUSS, H.H. 2003. Assessment and management of seafood safety and quality. Food Agriculture Organization (FAO). Fisheries Technical Paper 444.Rome:FAO.

11. KESTIN, S.C.; VAN DE VIS, J.W.; ROOB, D.H.F. Protocol for assessing brain function I fish and the effectiveness of methods used to stun and kill them. Veterinary Record, v. 150, p. 302307, 2002.

12. KUBITZA, F. "Off-flavor", nutrição, manejo alimentar e manuseio pré-abate afetam a qualidade do peixe destinado à mesa. Panorama da Aqüicultura, v.54, n.9, p.39-49, 1999.

13. LAMBOOIJ, E.; VAN DE VIS, J.W.; KUHLMANN, H.; MÜNKNER, W.; OEHLENSCHLÄGER, J.; KLOOSTERBOER, RJ.; PIETERSE, C. A feasible method for humane slaughter of eel (Anguilla anguilla $L$.): electrical stunning in freshwater prior to gutting. Aquaculture Research, v.33, p.643-652, 2002.

14. LAMBOOIJ, E.,. KLOOSTERBOER, R.J, GERRITZEN M.A.,. VAN DE VIS, J.W., Assessment of electrical stunning in freshwater of African Catfish (Clarias gariepinus) and chilling in ice water for loss of consciousness and sensibility. Aquaculture, v. 254, p. 388-395, 2006.

15. LIMA, L. C., RIBEIRO, L. P., LEITE, R. C., MELO, D. C. Estresse em peixes. Revista Brasileira de Reprodução Animal, Belo Horizonte, v. 30, n. 3/4, p. 113-117, 2006.

16. LINES, J., KESTIN, S., Electric stunning of trout: power reduction using a two-stagestun. Aquacultural Engineering 32 (2005) 483-491.

17. LOWE, T., RYDER, J.M., CARRAGER, J.F., WELLS, R.M.G., 1993. Flesh quality in snapper, Pagurus auratus, affected by capture stress. Journal of Food Science 58, 770-773.

18. MARDINI, C. V.; MARDINI L. B. Cultivo de peixes e seus segredos. Ed. Ulbra, 1aㅡ Ed. Canoas, RS, 2000, 204p

19. MARX, H., BRUNNER, B., WEINZIERL, W., HOFFMAN, R., STOLLE, A., 1997. Methods of stunning freshwater fish: impact on meat quality and aspects of animal welfare. Zeitschriftfur Lebensmittel-Unters uchun gund - Forschung 204, 282-286.

20. MORZEL,M.,SOHIER,D.,VANDEVIS,H.,2002.Evaluationofslaughtering methods for turbo twithre spectto animal welfare and fresh quality. Journal of the Science of Food and Agriculture 82, 19-28.

21. NUNES, M. L.; BATISTA, I.; CARDOSO C. Aplicação do Índice de qualidade (QIM) na avaliação da frescura do pescado. Lisboa: IPIMAR, 2007. $51 \mathrm{p}$.

22. OGAWA, M.; SILVA, A. I. M.; OGAWA, N. B. P.; MAIA, E. L.; NUNES. M. L. Adequações tecnológicas no processamento da carne de caranguejo. Ciênc. Tecnol. Aliment., Campinas, 28(1): 78-82, jan.-mar. 2008

23. OLSEN, S.H., SORENSEN, N.K., STONNO, S.K., ELVEVOLL, E.O., 2006. Effect of slaughter methods on blood spotting and residual blood in fillets of Atlantic salmon (Salmo salar). Aquaculture 258, 462-469.

24. PEDRAZZANI, A. S., O reconhecimento da senciência e proposta de método alternativo de abate. Dissertação de mestrado. UFPR, 2007. 
25. PedrazzANi, A. S., Neto, A. O., CARneiro, P. C. F., GAYer, M. V. e MOlento, C. F. M., Opinião pública e educação sobre abate humanitário de peixes no município de Araucária, Paraná, Ciência Animal Brasileira, v. 9, n. 4, p. 976-983, out./dez. 2008

26. PedRazZANI, A. S., MOlento, C. F. M., CARNeiRo, P. C. F., CASTILHO, M. F., Senciência e bem-estar de peixes: uma visão de futuro do mercado consumidor. Panorama da aquicultura, julho/agosto, 2007.

27. POLI, B.M.; PARISI, G.; SCAPPINI, F.; ZAMPACAVALLO, G. Fish welfare and quality as affected by pre-slaughter and slaughter management. Aquaculture International, v.13, p.29-49, 2005.

28. RIBAS, L., FLOS, R., REIG, L., MACKENZIE, S., BARTON, B. A., TORT, L. Comparison of methods for anaesthezing Senegal sole (Solea senegalensis) before slaughter: Stress responses and final product quality. Aquaculture, Amsterdam, v. 269, p. 250-258, 2007.

29. RIBEIRO, A. R.; PEREIRA, C. F. C.; JUSTUS, M. M.; PAPROSKI, R.; ALMEIDA, J. V. P.Manejo préabate e bioquímica da carne do pescado, Revista aqüicultura\& pesca, Ano I, n. 9, p. 24-33. 2005

30. ROBB, D.; KESTIN, S.; LINES, J. Progresswith humane slaughter. Fish Farmer. November/December 2000, 44p.

31. ROTH, B.; IMSLAND, A.; GUNNARSSON, S.; FOSS, A., SHELVIS-SMITH, R. Slaughter quality and rigor contraction in farmed turbot (Scophthalmus maximus); a comparison between different stunning methods. Aquaculture, Amsterdam, v. 272, p. 754-761, 2007.

32. ROTH, B.; VELAND, J.O.; MOELLER, D.; IMSLAND, A.; SLINDE, E. The effect of stunning methods on rigor mortis and texture properties of Atlantic salmon(Salmo salar). Journal of Food Science, v.67, p.1462-1466, 2002.

33. SOUZA, M. L. R., Industrialização, comércio e perspectivas. In: MOREIRA, H. L. M.; VARGAS, L.; RIBEIRO, L.P.; ZIMMERMANN, S. Fundamentos da Moderna Aquicultura. Ed. Ulbra, 2001, p. 149-189.

34. STANSBY, M. E. Industrial Fishery Technology. London: AVI, 1968,393p.

35. URBINATI, E. C.; CARNEIRO, P. C. F. Práticas de manejo e estresse dos peixes em piscicultura. In: CYRINO, J. E. P. et al. Tópicos especiais em piscicultura de água docetropical intensiva. São Paulo: TecArt, 2004. cap. 6, p. 171-193.

36. VAN DE VIS, J.W.; KESTIN, S.C.; ROBB, D.F.H.; OEHLENSCHLÄGER, J.; LAMBOOIJ, E.; MÜNKNER, W.; KUHLMANN, H.; MÜNKNER, W.; KLOOSTERBOER, R.J.; TEJADA M.; HUIDOBRO, A.; OTTERÅ, H.; ROTH, B.; SØRENSEN, N.K.; ASKE., L.; BYRNE, H.; AND NESVADBA, $P$. Is humane slaughter of fish possible for industry? Aquaculture Research, v.34, p.211-220, 2003.

37. VIEGAS, E. M. M. Rigor mortis em peixes, Pirassununga, SP, 2004. In: CASTAGNOLLI, N. Piscicultura de água doce. Ed. FUNEP, Jaboticabal, SP, 1994. 409p.

38. WENDELAAR BONGA, S.E. The Stress Response in Fish. Physiological Reviews, Boston, v. 77, n. 3, p. 591-625, 1997. 